\title{
Design of Cleaning Machine for Passenger Car Bogie
}

\author{
Jinling Zhao ${ }^{1, ~ a ~ a n d ~ M e i ~ T i a n ~}{ }^{2, b}$

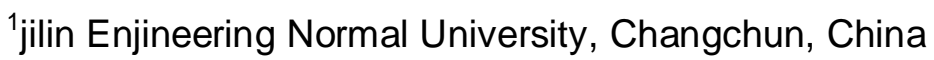 \\ a522927259@qq.com, b32593829@qq.com
}

Keywords: Bogie; Cleaning machine; Design; Technical parameter

\begin{abstract}
The thesis mainly of equipment overall design scheme, the cleaning process, equipment performance, structural characteristics, use effect were detailed, and main technical parameters of the equipment are calculated and checked, in order to provide a theoretical basis for the whole design process.
\end{abstract}

\section{Introduction}

Bogie frame design of cleaning machine main purpose is cleaning the steering frame of dirt and paint. For the next working procedure to frame is disassembled, the parts by shot peening and play sand provide prerequisites. At present, the main ways of cleaning such parts are: ultrasonic cleaning, high pressure water flow and alkali, water cleaning, etc. [1]The apparatus is high and alkali wash combined, the reason why the use of the cleaning method is due to the frame size is larger, the pollution is heavy, the two kinds of cleaning methods combined, the water impact force is greater than the dirt and surface adhesion, high pressure water will be dirt stripping, washed away, at the same time hot alkaline cleaning on the stubborn dirt, had little effect on the corrosion of the workpiece, is economical and practical way of cleaning. In addition, according to the whole process of the passenger car repair needs, fully utilize the energy, the small and medium-sized parts of the car washing can also be carried out in the steering frame cleaning room. $[2,3]$

\section{Cleaning Machine Plan}

The device according to the factory switched bus repair projects in the overall process arranged within the existing 48 meters long, wide 9 meters span workshop, in the design, the cleaning indoor storage of two steering frame and a cook wash tank design, one bogie in cleaning table, a in parking position. The cleaning room can realize the simultaneous cleaning of the bogie and the cooking and cleaning, and simultaneously, the water washing and the washing table of the steering frame and the small fittings are arranged at the same time. [4]To ensure that one pair of Passenger Car Bogies after the disintegration simultaneously into the washing step. Set the stack portal at the ends of cleaning the chamber, in order to achieve the bogie and cleaning tank respectively from both ends (along track) import. Control systems are manual control.

When the truck wash and cook tankers in and out of the cleaning chamber share a traction device, the device is also used in truck washing traction bogie reciprocate.

Injection pipeline system in the clear, alkaline each with a pump, and a common set of injection pipe, two rows ring nozzle in the cleaning chamber cleaning station position, the nozzle on the nozzle direction can be adjusted using the form. Cook and truck parts washed up washed separately using a water pump and setting up a pipeline system.[5]

Alkaline wall of steel and then poured concrete, and arranged in the ground position shown in Fig. 1. At the same time provided with a reflux system alkaline, alkaline to achieve recycling.

The clear water tank is a steel structure, which is arranged on the ground in Fig. 1.

An effective ventilation system is set up in the cleaning room. 


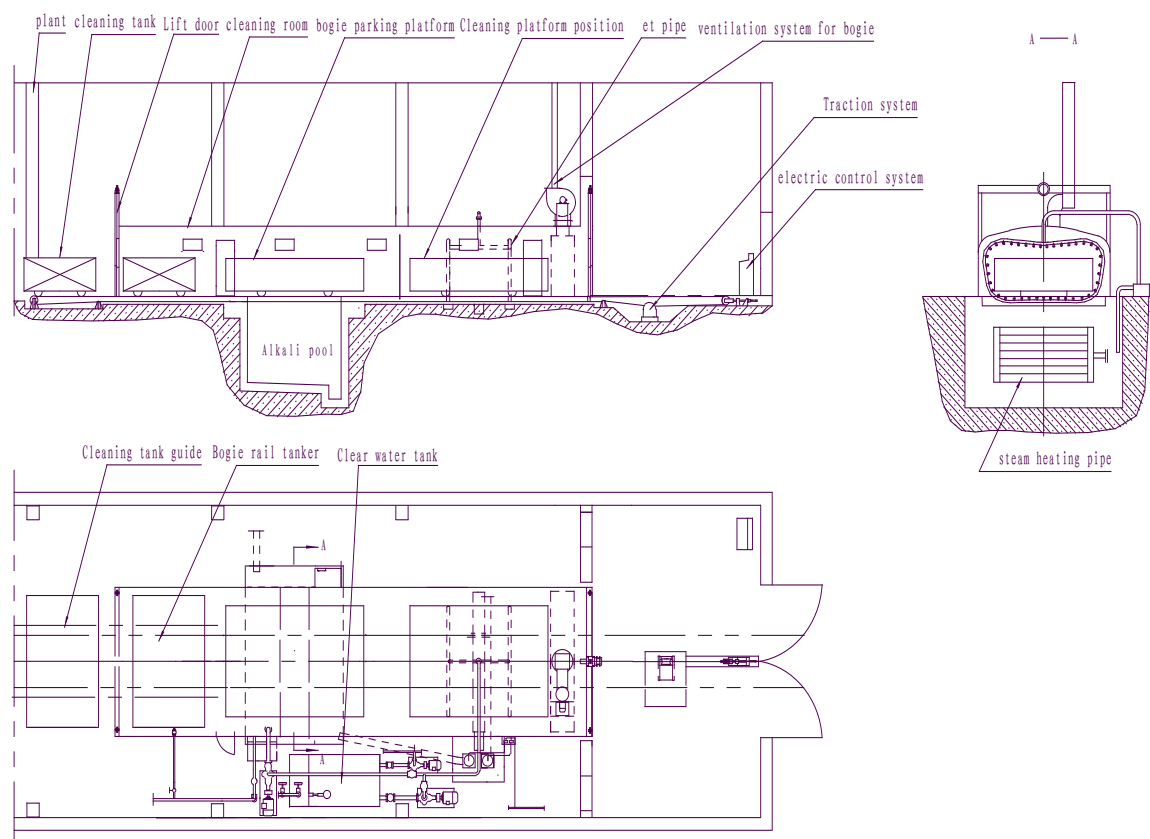

Figure 1. schematic diagram of the composition of the cleaning machine

\section{Cleaning Process}

Cleaning Process Flow of Bogie. The first steering frame to clean the indoor parking spaces $\rightarrow$ Second sets of bogie to clean the table $\rightarrow$ Second bogie in cleaning indoor reciprocating hot water flushing (salt water temperature of $80{ }^{\circ} \mathrm{C}$ ) about half an hour $\rightarrow$ Rinse water for 5 minutes $\rightarrow$ Pull the outdoor artificial feeding water wash $\rightarrow$ Using compressed air to blow the residual water $\rightarrow$ The first bogie to enter the cleaning stage to complete the second sets of the same washing process.

Washing Process of the Accessories for Small or Medium Sized. Middle and small accessories into the washing basket $\rightarrow$ Into the boiling wash tank of alkali water $\rightarrow$ Will pull to the tanker parked indoors cleaning table $\rightarrow$ Steam heating lye boil wash access 30 minutes $\rightarrow$ Cook wash tank traction to the outside $\rightarrow$ Hanging washing basket $\rightarrow$ Manual repair $\rightarrow$ Using compressed air to blow the residual water.

\section{Main Technical Parameters of the Bogie Cleaning Machine}

Workpiece maximum size $(\mathrm{L} \times \mathrm{W} \times \mathrm{H}) 1100 \mathrm{~mm} \times 3200 \mathrm{~mm} \times 4500 \mathrm{~mm}$.

The size of cleaning room $(\mathrm{L} \times \mathrm{W} \times \mathrm{H}) 2000 \mathrm{~mm} \times 4100 \mathrm{~mm} \times 15550 \mathrm{~mm}$.

The size of cook wash tank $(\mathrm{L} \times \mathrm{W} \times \mathrm{H}): 3800 \mathrm{~mm} \times 2200 \mathrm{~mm} \times 1100 \mathrm{~mm}$.

Reciprocating distance when the bogie flush : $1300 \times 2 \mathrm{~mm}$.

The method of heating salt water : steam direct heating.

Main parameters of installation equipment:

Alkali pump: power $15 \mathrm{KW}$, head $80 \mathrm{~m}$, flow $50 \mathrm{~m}^{3} / \mathrm{h}$;

Clear water pump: power $15 \mathrm{KW}$, head $50 \mathrm{~m}$, flow $50 \mathrm{~m}^{3} / \mathrm{h}$;

Cleaning pump: power $7.5 \mathrm{KW}$, head $47 \mathrm{~m}$, flow $30 \mathrm{~m}^{3} / \mathrm{h}$;

Fan: power $2.2 \mathrm{KW}$, air volume $5527 \mathrm{~m}^{3} / \mathrm{h}$;

Traction device: power $3 K W$; traction speed $4 \mathrm{~m} / \mathrm{min}$; maximum traction force $10 t$;

Door landing gear: power $2 \times 0.8 K W$, landing speed $30 \mathrm{~m} / \mathrm{min}$.

\section{Structural Characteristics of Cleaning Machine}

Cleaning Room. The main body of the cleaning room is carbon steel welded structure. [6]The indoor can realize the cleaning and storage of a pair of bogie, and the cooking and washing are 
carried out at the same time. Tanker truck wash and cook were out from both ends of the cleaning chamber. The gate stack is arranged at the two ends. The two sides of the cleaning room are provided with an observation window, which can be observed at any time to clean the room. The cleaning chamber is provided with a quick steam pipeline interface and is provided with a movable steam rubber pipe.[7]

Injection Pipeline System. According to the overall dimensions of the bogie, the cleaning station bit is set in two rows fixed annular nozzle spacing of $2 \mathrm{~m}$. Due to the fluid jet nozzles, under the action of air resistance, the flow rate decreases, the momentum theorem, the greater the distance of the nozzle from the workpiece, the jet force on the workpiece is smaller, so small from the cleaning effect. The distance is small washing area is also small, so the distance from the nozzle to the workpiece directly affect the cleaning quality of the workpiece. The analysis finds that taking the distance from the nozzle to the workpiece $300 \mathrm{~mm} \sim 350 \mathrm{~mm}$, with a row of 41 nozzles per nozzle spacing of about $215 \mathrm{~mm}$. Nozzle made of stainless steel, cross-sectional shape of a fan, spray angle adjustable. Fig. 2:

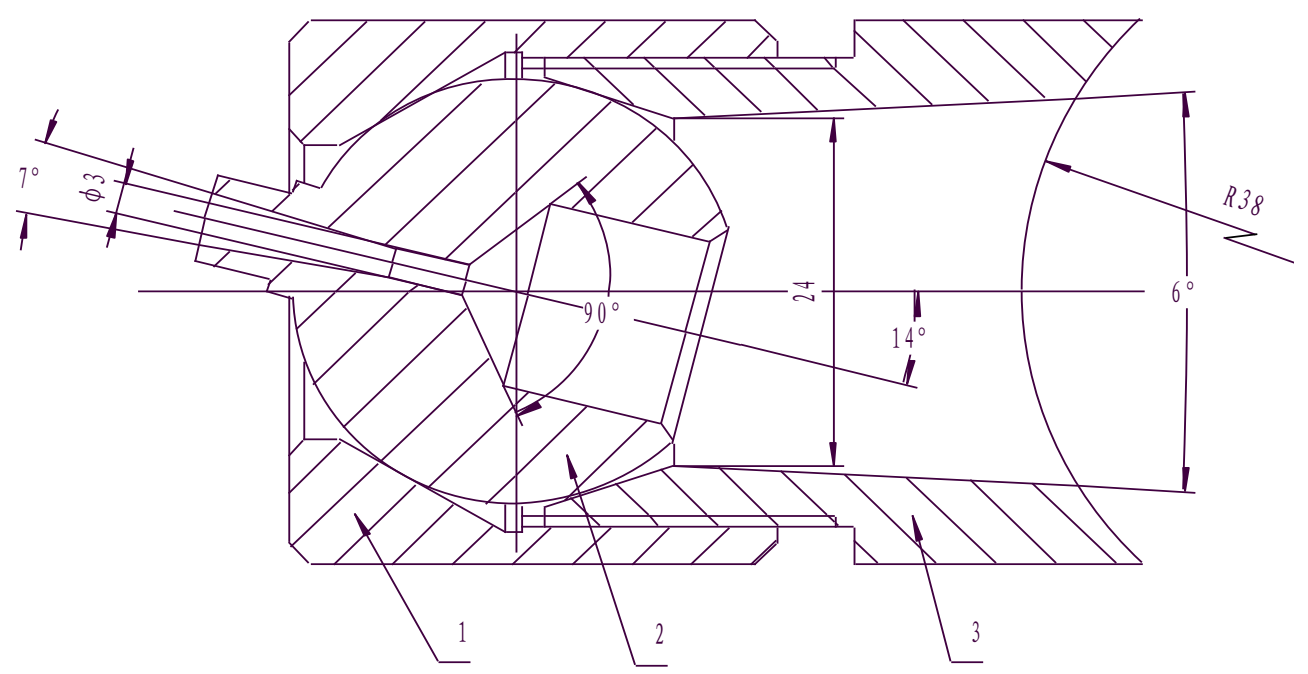

1. nut 2. nozzle sphere 3. joint body

Figure 2. Nozzle structure

The Device of Traction . Traction device includes a winch means, guide wheels, fixed pulley, wire rope, tensioning device, traction fixtures, limit switches and the like. The electrical control of the bogie and the cleaning tank pull in pull. When the bogie is cleaned, the traction bogie does reciprocating motion, and the left and right travel of each $1300 \mathrm{~mm}$. Traction speed $4 \mathrm{~m} / \mathrm{min}$.

\section{Design Calculation}

The design calculation of the cleaning machine mainly includes the design calculation of the steel structure of the cleaning room, the design calculation of the injection pipe, the design calculation of the traction system, the ventilation system and so on. The design and calculation of injection pipe and traction system are introduced here.[8]

Injection Line Calculation. Process requirements: Two rows of annular jet pipe, pipe diameter $d_{1}=50 \mathrm{~mm}$, a total length of 9 meters, a number of 41 single line nozzle, exit flow pressure $P_{\text {out }}=1 \mathrm{MPa}$, export diameter $d_{2}=3 \mathrm{~mm}$, the average height of exports from the ground is $500 \mathrm{~mm}$. As shown in Fig. 3: 


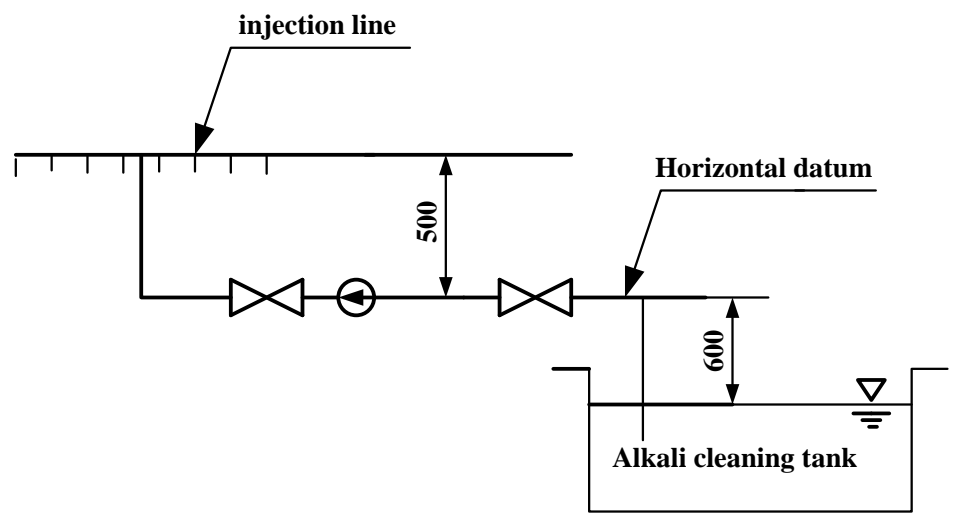

Figure 3. injection piping system

Resistance Calculation. Flow types: Circular: $\operatorname{Re}=v_{1} d_{1} / \gamma$ (Average velocity of water pipeline $v_{1}=2.5 \mathrm{~m} / \mathrm{s}$, Kinematic viscosity coefficient of water at normal temperature $\gamma=1.007 \times 10^{-6} \mathrm{~m}^{2} / \mathrm{s}$ ). Therefore, $\operatorname{Re}=124131 \succ 2300 \mathrm{~m}^{2} / \mathrm{s}$, for turbulent flow.

Resistance loss: $\Delta P w=\Delta P e+\Delta P r$

Resistance loss along the path $\Delta P e=\lambda l / d \times \rho v_{1}^{2} / 2$, Drag coefficient $\lambda=0.038 /(0.842-\lg \operatorname{Re})^{2}=0.02$, so $\triangle P e=0.02 M P a$

Local resistance loss $\Delta \operatorname{Pr}=\sum \xi \times \rho v_{1}{ }^{2} / 2$ ( $\xi$ is the local resistance coefficient, Which gate valve $2 \xi_{1}=1.3 ;$ Entrance $\xi_{2}=0.5 ;$ Export 82, $\xi_{3}=0.3 ;$ Shrink diameter $82, \xi_{4}=\xi^{\prime}\left(1-A_{2} / A_{1}\right)=0.41\left[1-(3 / 50)^{2}\right]=0.4 ; 82$ pipeline expansion, $\xi_{5}=0.05 ;$ Branch pipe $\xi_{6}=1.3 ;$ Elbow $\xi_{7}=0.13$.two).

So, $\Delta \operatorname{Pr}=\left(2 \xi_{1}+\xi_{2}+82 \xi_{3}+82 \xi_{4}+82 \xi_{5}+\xi_{6}+2 \xi_{7}\right) \times \rho v_{1}^{2} / 2=0.1 M P a$

$\triangle P w=0.12 M P a$

Pump Outlet Pressure Calculation. For pipeline and export $v_{1} A_{1}=42 v_{2} A_{2}$, so $v_{2}=v_{1} / 42 \times\left(d_{1} / d_{2}\right)^{2}=16.5 \mathrm{~m} / \mathrm{s}$, Flow $Q=2 v_{1} A_{1}=36 \mathrm{~m}^{3} / \mathrm{h}$; taking the horizontal ground as the datum plane, the Bernoulli equation of the base water pool surface and the jet plane column is:

$$
\begin{aligned}
& P_{\text {pump }}-Z_{1} \rho g+0=P_{\text {out }}+\Delta P w+Z_{2} \rho g+\rho v_{2}^{2} / 2 \\
& P_{\text {pump }}=P_{\text {out }}+\Delta P w+Z_{2} \rho g+\rho v_{2}^{2} / 2+Z_{1} \rho g \approx 1.22 \mathrm{MPa}
\end{aligned}
$$

Motor power: $N=P_{\text {pump }} Q / \eta(\eta=0.7)=11.4 K W$

According to the above calculation, the pump head $80 \mathrm{~m}$, flow $50 \mathrm{~m}^{3} / \mathrm{h}$, power $15 K W$.Reference to the above calculation, take the water pump head $50 \mathrm{~m}$, flow $50 \mathrm{~m}^{3} / \mathrm{h}$, power $15 K W$.

Traction System Calculation. Process requirements: Mainly consists of five parts: motor, reducer, drum, steel wire rope, pulley. Traction tonnage: cleaning equipment weight $10 t$; bogie weight: $7 T$, two do not work at the same time, namely the maximum traction tonnage is $10 t$. Traction speed: $4 \mathrm{~m} / \mathrm{min}$. [9]

The principle of design: Traction system working principle is mainly motor is reducer reducer, drives the drum to rotate at a speed, while driving wound on the reel wire rope straight reciprocating motion, in the steel wire rope is fixed with a clamp ring, [10] to clamp the boiling wash equipment and bogie, boiling washing equipment and steering frame in the reciprocating motion of the wire rope is pull in and pull-out cleaning room. By the above structure, the rotating motion of the motor 
is changed into the linear motion of the bogie.

Parameter calculation:

Determination of motor power: rail maximum static friction coefficient: $\mu=0.15$;

Maximum static tension: $S_{\max }=\mu N=1500 \mathrm{Kg}=14700(N)$;

Power: $p=0.99^{4} \times 0.95 \times 0.85^{4} \times 0.95=0.45$

The total power of motor: $P=p / \eta=2.2 \mathrm{KW}$ take $p=3 \mathrm{KW}$

Select Y series motor Level $4 n=1450 \mathrm{r} / \mathrm{min} ; p=3 K W$

Choice of model of reducer: reel output line speed: $v=4 \mathrm{~m} / \mathrm{min}$; reducer output speed:

$v=\pi d n / 1000, n=1000 v / \pi D_{1}=5.3 r / \mathrm{min}$; transmission ratio: $I=1450 / 5.3=273$, selection:

Nominal transmission ratio: $I=289$.Reducer model: XWEY3-84-289-B3

\section{Conclusions}

The equipment has been delivered, the equipment running in good condition. This device not only to achieve the desired effect, and create favorable conditions for the smooth conduct of bus repair, and manufacturing costs for the plant to save a hundred thousand dollars. Meanwhile, in the design fully consider the health effects of corrosion and alkali vapor generated during the cleaning of the plant for workers and improve the working environment for workers.

\section{References}

[1] H. Xu: Mechanical Design Handbook (Mechanical Industry Press, China, 2001). (In Chinese)

[2] Y.Q. Nie and G.W. Meng: Mechanics of Materials (Mechanical Industry Press, China, 2009). (In Chinese)

[3] J.W. Wang: Hydraulic Transmission (Mechanical Industry Press, China, 2007). (In Chinese)

[4] X.K.Jin: Mechanical Engineering Mechanics (Higher Education Press, China, 2001). (In Chinese)

[5] X.Wang: Journal of Railway Engineering Society, (2008) No.4, p.91. (In Chinese)

[6] F.Y.Huang, Y.M.Mo, Y.Li and L.H.Wu: Railway Vehicles, Vol.43 (2005) No.6, p.33. (In Chinese)

[7] Y.M.Zhang and H.Yin: Railway Vehicles, Vol.46 (2008) No.9, p.39. (In Chinese)

[8] F.Q.Li, Y.G.Zhao and P.F.Guo: Locomotive \& Rolling Stock Technology, (2015) No.4, P. 38. (In Chinese)

[9] J.P.Feng and J.B.Zhang: Sci/Tech Information Development \& Economy, Vol.18 (2008) No.8, p.210. (In Chinese)

[10] Y.Li, Y.Wang, P.Wang, P.Li, K.M.Wang and J.Wang: Technology and Market, Vol.21 (2014) No.7, p.1. (In Chinese) 